\title{
InterCriteria Analysis of body composition measurements data, associated with obesity among college students Simeon Ribagin ${ }^{1,2}$, Antoaneta Grozeva ${ }^{2}$, Gergana Popova ${ }^{2}$ and Zlatina Stoyanova ${ }^{2}$ \\ ${ }^{1}$ Bioinformatics and Mathematical Modelling Department, Institute of Biophysics and Biomedical Engineering, Bulgarian Academy of Sciences 105 Acad. Georgi Bonchev Str., Sofia 1113, Bulgaria e-mail: simribagin@gmail.com \\ ${ }^{2}$ Department of Health and Social Care, Medical College University "Prof. D-r Asen Zlatarov", Burgas, Bulgaria e-mails: antoaneta.grozeva@gmail.com, giggi_popa@abv.bg, zlatina.s.borisova@jmail.com
}

Received: 25 June 2019

Accepted: 7 October 2019

\begin{abstract}
This study assessed the body composition indices associated with overweight/obesity among students at Medical College of University "Prof. Dr. Asen Zlatarov" in Burgas and also to verify the test assessment methods using the application of InterCriteria Analysis (ICA) to the data obtained from the tests. The data was analyzed in search of correlations between the results from the method of testing for some anthropometric measurements and certain findings are outlined and commented.
\end{abstract}

Keywords: Physical activity, University students, InterCriteria Analysis, Intuitionistic fuzzy sets. 2010 Mathematics Subject Classification: 03E72.

\section{Introduction}

Obesity is defined as excess or abnormal fat mass [5]. It is estimated worldwide that there are 1.2 billion overweight people with obesity affecting 300 million of them [9]. Anthropometric indices are widely used for evaluation of health, nutrition risks and in people of all ages. The most common measure of overweight and obesity is the Body Mass Index (BMI), which is determined by the individual's weight and height. Individuals with a BMI of 30 or higher are 
considered to be obese, while individuals with a BMI between 25 and 29.9 are considered to be overweight [10]. Visceral fat is a type of body fat that's stored within the abdominal cavity. It's located near several vital organs, including the liver, stomach, and intestines. Belly fat can also be subcutaneous fat, stored just under the skin. Body fat includes essential body fat and storage body fat. Essential body fat is a base level of fat that is found in most parts of the body. It is necessary fat that maintains life and reproductive functions. The amount of essential fat differs between men and women, and is typically around $2-5 \%$ in men, and $10-13 \%$ in women. The healthy range of body fat for men is typically defined as $8-19 \%$, while the healthy range for women is $21-33 \%$. According to [7], 30 to 40 percent of a healthy person's body mass is made up of skeletal muscle.

In this paper we propose the application of the approach of InterCriteria Analysis (ICA) to anthropometric data, obtained from college students. The data was analyzed in search of correlations between the indices in order to predict the reliability of the proposed method of evaluation of the overweight/obesity among the participants.

\section{Presentation of the input data}

The investigation and the data collection process, has been carried out in the educational year 2019/20. Contingent of the investigation are 30 students (10 males and 20 females), aged 18-51 years in Medical College of University "Prof. Dr. Asen Zlatarov" in Burgas. All subjects agreed to provide their personal information regarding the purpose and the procedures of our study, and written informed consent. Height was measured to the nearest $0.1 \mathrm{~cm}$ with a standard stadiometer following study protocols, and weight in kilograms was measured in light clothing to the nearest $0.1 \mathrm{~kg}$ on an electronic scale. All anthropometric data were collected by trained staff with the "OMRON BF511" body composition monitor. This device provides extensive insight in body and visceral fat, skeletal muscle level, BMI and resting metabolism. It is clinically validated and classified as a medical device [8]. The results from the anthropometric measurements, as an input data with a given weight are represented by seven criteria: C1 (age), C2 (high), C3 (weight), C4 (BMI), C5 (Body fat), C6 (Skeletal muscle), C7 (Visceral fat).

\section{Application of the InterCriteria Analysis}

The method of InterCriteria Analysis (ICA) is based on intuitionistic fuzzy sets, thus rendering account of the effects of uncertainty. Originally, ICA was being proposed in [2], and various aspects of its theoretical investigation are given in papers [1, 3, 4].

For this aim, we use the developed software for InterCriteria Analysis [6] (freely available online at: http://intercriteria.net/software) and feed it with the data from the two control groups of students. The complete resultant tables with InterCriteria intuitionistic fuzzy membership pairs are given on Table 1 and Table 2. 


\begin{tabular}{|c|c|c|c|c|c|c|c|}
\hline & $\mathbf{C 1}$ & $\mathbf{C 2}$ & $\mathbf{C 3}$ & $\mathbf{C 4}$ & $\mathbf{C 5}$ & $\mathbf{C 6}$ & $\mathbf{C 7}$ \\
\hline $\mathbf{C 1}$ & 1.000 & 0.4945 & 0.4725 & 0.4396 & 0.3297 & 0.5604 & 0.5385 \\
\hline C2 & 0.4945 & 1.000 & 0.6044 & 0.5055 & 0.4396 & 0.6044 & 0.5165 \\
\hline C3 & 0.4725 & 0.6044 & 1.000 & 0.9011 & 0.7692 & 0.3516 & 0.8022 \\
\hline C4 & 0.4396 & 0.5055 & 0.9011 & 1.000 & 0.8242 & 0.2857 & 0.7692 \\
\hline C5 & 0.3297 & 0.4396 & 0.7692 & 0.8242 & 1.000 & 0.1209 & 0.6484 \\
\hline C6 & 0.5604 & 0.6044 & 0.3516 & 0.2857 & 0.1209 & 1.000 & 0.3297 \\
\hline C7 & 0.5385 & 0.5165 & 0.8022 & 0.7692 & 0.6484 & 0.3297 & 1.000 \\
\hline
\end{tabular}

Table 1. Results of the application of the InterCriteria Analysis on the aggregated data of the female participants, IF membership parts

\begin{tabular}{|c|c|c|c|c|c|c|c|}
\hline & $\mathbf{C 1}$ & $\mathbf{C 2}$ & $\mathbf{C 3}$ & $\mathbf{C 4}$ & $\mathbf{C 5}$ & $\mathbf{C 6}$ & $\mathbf{C 7}$ \\
\hline $\mathbf{C 1}$ & 1.000 & 0.5333 & 0.2222 & 0.1778 & 0.2444 & 0.4444 & 0.1556 \\
\hline C2 & 0.5333 & 1.000 & 0.3556 & 0.2222 & 0.3111 & 0.5333 & 0.2000 \\
\hline C3 & 0.2222 & 0.3556 & 1.000 & 0.8667 & 0.8222 & 0.2222 & 0.8444 \\
\hline C4 & 0.1778 & 0.2222 & 0.8667 & 1.000 & 0.8222 & 0.2444 & 0.9778 \\
\hline C5 & 0.2444 & 0.3111 & 0.8222 & 0.8222 & 1.000 & 0.1111 & 0.8000 \\
\hline C6 & 0.4444 & 0.5333 & 0.2222 & 0.2444 & 0.1111 & 1.0000 & 0.2444 \\
\hline C7 & 0.1556 & 0.2000 & 0.8444 & 0.9778 & 0.8000 & 0.2444 & 1.0000 \\
\hline
\end{tabular}

Table 2. Results of the application of the InterCriteria Analysis on the aggregated data of the male participants, IF membership parts

From the results of the female control group, we see that the pairs with the strongest positive consonance, i.e. those with smallest distance from the intuitionistic fuzzy truth $\langle 1,0\rangle$, are those detected between the C4 (BMI) - C7 (Visceral fat), C4 (BMI) - C3 (Weight) and C5 (Body fat \%) - C4 (BMI). These pairs are formed between logically related indicators, but there is a significant difference in males and females particularly in relation between BMI and visceral fat. The graphical representation of the results is presented on Figure 1 and Figure 2. 

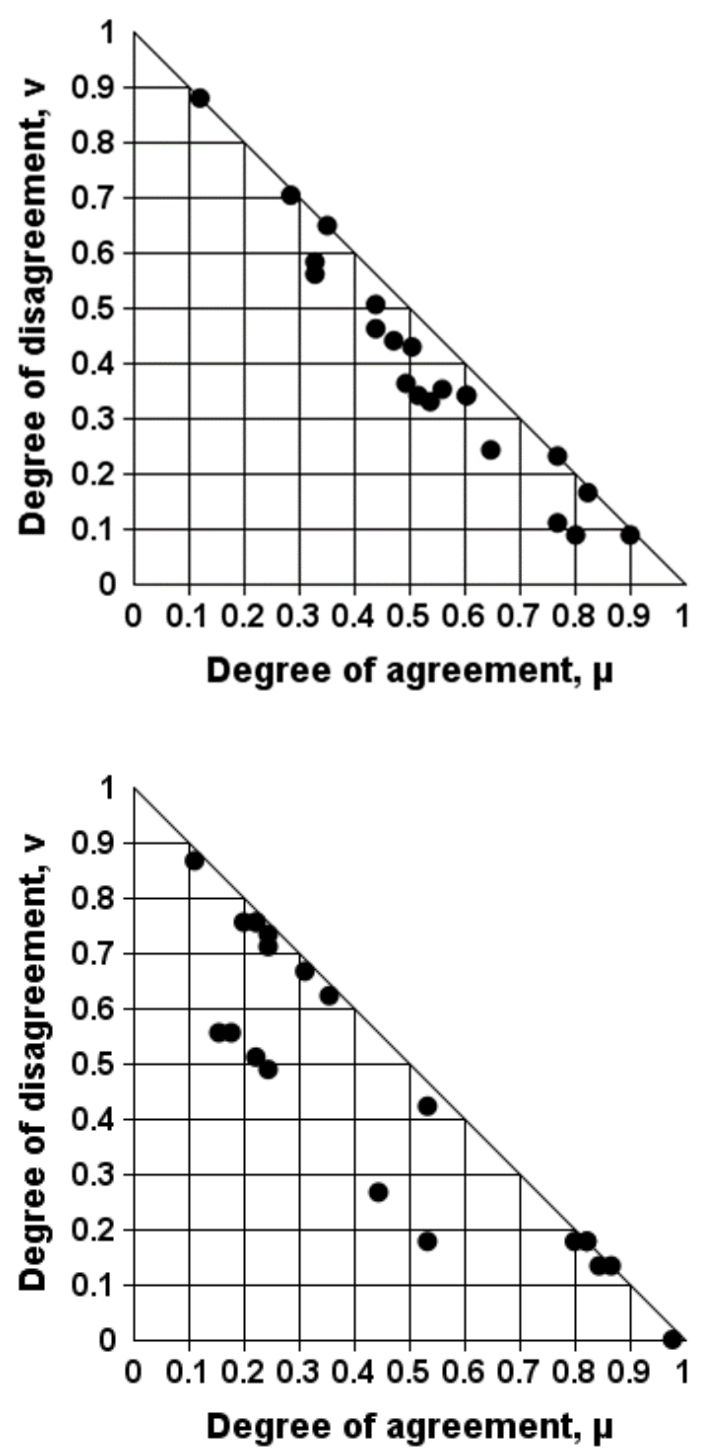

Figure 1. InterCriteria pairs between the 7 criterions (Table 2) from the results of the female participants, as plotted as points (black) on the intuitionistic fuzzy interpretational triangle.

Figure 2. InterCriteria pairs between the 7 criterions (Table 2) from the results of the male participants, as plotted as points (black) on the intuitionistic fuzzy interpretational triangle.

\section{Conclusions}

This study describes a new method of processing anthropometric data obtained from college students and after the application of ICrA several conclusions can be made:

- BMI strongly correlates with visceral fat, only in male participants,

- BMI strongly correlates with body fat \%, only in female participants.

Our findings support the importance of taking gender in to consideration when using BMI to predict body fat percentage/obesity. Body Mass Index uses weight in the formula but unfortunately it does not take into account if that weight comes from fat rather than lean muscle tissue. Naturally, given the relatively small size of the considered data it is not possible to claim with absolute certainty that our interpretations are doubtlessly valid but they provide a starting point for further investigations. 


\section{Acknowledgements}

The first author is grateful for the support provided under Grant No. KP-06-N-22-1 "Theoretical research and applications of the InterCriteria Analysis' funded by the National Science Fund of Bulgaria. For the data collection, the authors are grateful for the support provided under Grant No. NIH-411/2018 "Study on the possibilities of complex rehabilitation and medicinal products in overweight children and students" of "Prof. Asen Zlatarov" University, Burgas, Bulgaria.

\section{References}

[1] Atanassov, K., Atanassova, V. \& Gluhchev, G. (2015). InterCriteria Analysis: Ideas and problems, Notes on Intuitionistic Fuzzy Sets, 21 (1), 81-88.

[2] Atanassov, K., Mavrov, D., \& Atanassova, V. (2014). Intercriteria Decision Making: A New Approach for Multicriteria Decision Making, Based on Index Matrices and Intuitionistic Fuzzy Sets. Issues in Intuitionistic Fuzzy Sets and Generalized Nets, 11, $1-8$.

[3] Atanassov, K., Szmidt, E., Kacprzyk, J., \& Atanassova, V. (2017). An approach to a constructive simplification of multiagent multicriteria decision making problems via intercriteria analysis. Comptes rendus de l'Academie bulgare des Sciences, 70 (8), $1147-1156$.

[4] Atanassova, V. (2015). Interpretation in the Intuitionistic Fuzzy Triangle of the Results, Obtained by the InterCriteria Analysis, $16^{\text {th }}$ World Congress of the International Fuzzy Systems Association (IFSA), $9^{\text {th }}$ Conference of the European Society for Fuzzy Logic and Technology (EUSFLAT), 30.06 - 03.07.2015, Gijon, Spain, 1369-1374.

[5] Ellulu, M., Abed, Y., Rahmat, A., Ranneh, Y., \& Ali, F. (2014). Epidemiolgy of obesity in developing countries: challenges and prevention. Glob. Epidemic Obes., doi: 10.7243/2052-5966-2 (6 pages).

[6] Ikonomov, N., Vassilev, P., \& Roeva, O. (2018). ICrAData - Software for InterCriteria Analysis, Int J Bioautomation, 22 (1), 1-10.

[7] Heymsfield, S., (2005). Human Body Composition, Human Kinetics, 2005, 0736046550, 9780736046558.

[8] Westphal, A., B., et al., (2008). Accuracy of Bioelectrical Impedance Consumer Devices for Measurement of Body Composition in Comparison to Whole Body Magnetic Resonance Imaging and Dual X-Ray Absorptiometry, December 2008, Obesity Facts, 1 (6), 319-24, DOI: 10.1159/000176061.

[9] Willborn C.,et.al., (2005). Obesity: Prevalence, theories, medical consequences, management, and research directions. J. Int. Soc. Sports Nutr. 2005 (2), 4-31. doi: $10.1186 / 1550-2783-2-2$.

[10] World Health Organization, WHO Mean Body Mass Index (BMI). Retrieved 5 February 2019. 